\title{
Pengembangan Soal Literasi Matematika Berbasis Kearifan Lokal Minahasa Untuk Siswa SMP
}

\author{
Derel Filandy Kaunang ${ }^{1}$ \\ Universitas Negeri Manado \\ e-mail: derelkaunang@unima.ac.id \\ Jeane Mantiri ${ }^{2}$ \\ Universitas Negeri Manado \\ Navel Oktaviandy Mangelep ${ }^{3}$ \\ Universitas Negeri Manado
}

\begin{abstract}
ABSTRAK
Tujuan penelitian ini adalah untuk menghasilkan soal literasi matematika yang dikaitkan dengan kearifan lokal Minahasa mengingat siswa sudah sangat familiar dengan kearifan lokal yang mereka lihat dan temukan sehari-hari. Dalam penelitian ini dihasilkan soal literasi matematika yang valid dan praktis. Metode penelitian yang digunakan adalah metode penelitian pengembangan (development research) yang terdiri dari tahap preliminary (analisis dan desain) dan prototiping (evaluasi formatif). Subjek penelitian ini adalah siswa kelas VIII SMP Kristen Woloan. Teknik pengumpulan data antara lain walk through, dokumentasi, wawancara, dan tes. Berdasarkan hasil pengembangan diperoleh prototipe perangkat soal untuk kompetensi literasi matematika yang valid dan praktis. Kevalidan dipenuhi berdasarkan validasi secara kualitatif dan kuantitatif. Sedangkan kepraktisan ditunjukkan bahwa para ahli/praktisi telah menyatakan bahwa soal yang dikembangkan dapat diterapkan pada siswa SMP, selain itu sesuai pelaksanaan pada tahap one-to-one dan small group, terlihat bahwa semua siswa dapat menggunakan perangkat soal dengan baik.
\end{abstract}

\section{Kata kunci: Pengembangan Soal Literasi Matematika, Kearifan Lokal Minahasa}

\section{ABSTRACT}

The aim of this research was to produce mathematics literacy problem that were associated with Minahasa local wisdom, considering that students were very familiar with the local wisdom that they saw and found everyday. In this study a valid and practical mathematical literacy problem was produced. The research method used is the method of development research (development research) which consists of the preliminary stage (analysis and design) and prototiping (formative evaluation) This research was conducted on Second grade students at SMP Kristen Woloan. Data collection techniques include walk through, documentation, interviews, and tests. The results of the study showed that the development obtained a prototype of the question device for mathematical literacy competencies that are valid and practical. Validity is fulfilled based on qualitative and quantitative validation. Whereas practicality is shown that experts/ practitioners have stated that the questions developed can be applied to junior high school students, besides that according to the implementation of the one-to-one and small group step, it can be seen that all students can use the questioning instruments well.

Keywords: Development of Mathematics Literacy Problem, Minahasa Local Wisdom

\section{PENDAHULUAN}

Kontes Literasi Matematika (KLM) wilayah Sulawesi Utara yang telah dilaksanakan beberapa tahun terakhir yakni tahun 2015 dan 2016 menghasilkan pemenang dari sekolahsekolah yang berada di perkotaan (p4mriunima.wordpress.com).
Kenyataan memperlihatkan bahwa sekolah-sekolah yang berada di desa terlihat sangat sulit untuk berada di rangking atas dalam Kontes Literasi Matematika (KLM) wilayah Sulawesi Utara dalam beberapa tahun terakhir sejak dilaksanakan tahun 2014. 
Salah satu faktor penyebab permasalahan di atas adalah kurang pahamnya siswa dalam menyelesaikan masalah dalam kehidupan sehari-hari yang berkaitan dengan matematika, padahal soal-soal dalam literasi matematika erat kaitannya dengan kehidupan sehari-hari.

Provinsi Sulawesi Utara khususnya di Minahasa terdapat beberapa kearifan lokal yang erat kaitannya dengan kehidupan sehari-hari. Beberapa kearifan lokal Minahasa yang dimaksud diantaranya rumah tradisional Minahasa (Gosal, Pierre Holly 2012) yang terletak di di desa Woloan dan kerajinan kayu di desa Leilem.

Rumah tradisional Minahasa yang terbuat dari kayu dapat dikaji unsurunsur di dalam rumah antara lain, bentuk atap, pola plafon dan dinding yang banyak kaitannya dengan matematika. Begitu juga, kerajinan kayu di desa Leilem yang masih terdapat pembuatan roda yang terbuat dari kayu untuk kendaraan di sawah yang biasa digunakan masyarakat untuk bertani. Pembuatan roda ini tentunya erat kaitannya dengan bentuk lingkaran yang merupakan bagian dari matematika. Halhal seperti inilah yang sebenarnya sangat familiar dengan siswa yang bersekolah di sekitaran lokasi pembuatan Rumah Tradisional Minahasa dan kerajinan kayu. Saputra (dalam Dwi Astuti Linda, 2016) menjelaskan bahwa dengan pengintegrasian budaya lokal pada pendidikan merupakan suatu hal yang sangat penting untuk mengisi elemen budaya dan membuat budaya lebih kuat dan mampu bertahan dari era globalisasi.

Oleh sebab itu, tujuan penelitian penelitian ini adalah mengembangkan perangkat pembelajaran berbasis kearifan lokal Minahasa untuk meningkatkan kemampuan literasi matematika siswa sekolah menengah pertama. Pengembangan perangkat yang berbasis kearifan lokal Minahasa tentunya akan memudahkan siswa dalam memahami materi karena siswa sudah sangat familiar dengan kearifan lokal yang biasa mereka lihat sehari-hari.

Adapun rumusan masalah dalam penelitian ini adalah bagaimana mengembangkan perangkat pembelajaran berbasis kearifan lokal Minahasa untuk meningkatkan kemampuan literasi matematika siswa sekolah menengah pertama ? Oleh karena itu luaran/produk yang dihasilkan dalam penelitian ini adalah produk perangkat pembelajaran yang terdiri dari RPP, LKS, bahan ajar dan tes evaluasi yang dapat digunakan oleh guru dalam pembelajaran untuk memudahkan siswa memahami matematika yang mana dapat meningkatkan literasi siswa sekolah menengah pertama.

Penelitian ini sangat penting untuk dilaksanakan karena dapat membantu para guru mengatasi kesulitan siswa dalam memahami matematika dan tentunya akan meningkatkan kemampuan literasi matematika siswa sekolah menengah pertama agar dapat bersaing dalam Kontes Literasi Matematika yang akan dilaksanakan tahun berikutnya.

\section{METODE}

Penelitian ini menggunakan metode penelitan pengembangan (development research). Dalam penelitian ini terdiri dari tahap preliminary yaitu analisis, pendesainan, dan evaluasi formatif (Akker, 2006).

Pada tahap preliminary merupakan langkah awal penelitian pengembangan. Untuk tahap persiapan peneliti menentukan subjek penelitian dengan cara menghubungi kepala sekolah dan 
berkoordinasi dengan guru mata pelajaran matematika di sekolah yang menjadi subjek penelitian, serta dilakukan persiapan-persiapan lain seperti mengatur jadwal penelitian dan prosedur kerjasama yang dilaksanakan. Peneliti dalam hal ini menganalisis siswa, analisis kurikulum dalam pembelajaran.

Selanjutnya pada tahap pendesainan peneliti mendesain perangkat soal literasi matematika berbasis kearifan lokal Minahasa yang digunakan untuk mengetahui pemahaman siswa dalam menyelesaikan soal yang berkaitan dengan kehidupan sehari-hari. Adapun hasil pendesainan ini dinamakan prototipe I.

Pada tahap Evaluasi Formatif (Formative Evaluation) terdiri atas:

\section{a) Self Evaluation}

Pada tahap ini peneliti melakukan penilaian sendiri terhadap prototipe yang telah dibuat, atau menilai sendiri hasil pada tahap sebelumnya (pendesainan). Peneliti mengkaji sendiri hasil desain yang telah dibuat. Tahapan ini menghasilkan prototipe II.

b) Expert Review (Uji Pakar)

Hasil penilaian dari peneliti diberikan atau dikonsultasikan kepada pakar sebagai Validator termasuk diberikan kepada guru mata pelajaran matematika, dan kepada teman sejawat untuk menelaah konten, konstruk dan bahasa. Komentar digunakan untuk merevisi desain prototipe. Komentar atau saran yang diberikan validator akan mendasari peneliti untuk melakukan perbaikan (Revise) perangkat pembelajaran yang telah dikembangkan. Tanggapan dan saran validator ditulis pada lembar validasi sebagai bahan perbaikan dan bukti bahwa perangkat pembelajaran dikembangkan telah valid. Berdasarkan karekteristik di atas, hasil desain prototipe yang telah divalidasi oleh pakar, dan yang telah dinilai oleh peneliti sendiri (Triangulasi Data) menghasilkan prototipe III.

c) One to one

Tahapan ini dilakukan secara paralel dengan tahap Expert Review. Pada tahap ini prototipe pertama diuji coba satu-satu kepada peserta didik. Uji satu-satu ini terdiri dari satu orang peserta didik berkemampuan tinggi, satu orang peserta didik berkemampuan sedang, dan satu orang peserta didik berkemampuan rendah (ditentukan berdasarkan konsultasi dengan guru mata pelajaran). Hasil uji coba yang dimaksudkan adalah jawaban, komentar serta saran peserta didik untuk kedua dan dikonsultasikan kepada pakar sehingga menghasilkan prototipe ketiga.

d) Small Group

Prototipe ketiga kemudian diujicobakan pada small group (kelompok kecil). Pada uji coba ini terdiri dari enam orang peserta didik diantaranya dua orang peserta didik berkemampuan tinggi, dua orang peserta didik berkemampuan sedang, dan dua orang peserta didik berkemampuan rendah untuk melihat hasil kerja peserta didik, apakah telah merasa jelas dan mampuh menyelesaikan prototipe ketiga.Hasil dari tahap ini dijadikan bahan untuk merevisi dan mendapat hasil prototipe keempat.

e) Field Test

Pada tahap ini dilakukan uji coba pada kelompok peserta didik dengan menggunakan prototipe keempat. Prototipe keempat ini merupakan 
hasil revisi prototipe ketiga yang telah memenuhi kriteria kualitas Akker, 1999 (Mangelep, 2013) yaitu bahwa tiga kriteria kualitas adalah validitas, kepraktisan, dan efektifitas (memiliki efek potensial).

Penggunaan teknik dalam mengumpulkan data pada penelitian ini adalah:

a. Dokumentasi

Pengumpulan data dokumentasi dilaksanakan pada tahap Self evaluation, one to one, dan tahap small group. Pada tahap Self evaluation, data yang dikumpulkan berupa kearifan lokal Minahasa dalam hal ini rumah tradisional Minahasa dan kerajinan kayu, kurikulum yang digunakan di sekolah SMP Kristen Woloan dan dokumen pendukung lainnya yang kemudian dijadikan landasan dalam mengembangkan perangkat pembelajaran.

b. Walk Through

Dilakukan pada tahap expert reviewoleh pakar untuk memberikan masukan terhadap kejelasan perangkat pembelajaran yang dikembangkan. Prosedur dalam melaksanakan tahap ini yaitu sebagai berikut; (1) peneliti memberikan hasil pengembangan prototipe pertama kepada pakar serta guru mata pelajaran matematia serta teman sejawat; (2) pakar beserta guru mata pelajaran matematika dan teman sejawat mengevaluasi prototipe yang ada pada prototipe pertama kemudian memberikan komentar atau saran perbaikan pada lembar instrumen yang ada; (3) peneliti melakukan perbaikan terhadap prototipe dengan mempertimbangkan semua komentar dan saran dari pakar atau pembimbing, guru mata pelajaran matematika dan teman sejawat.

c. Tes

Tes dilaksanakan pada tahap terakhir yaitu field test dimana prototipe yang telah dikembangkan hingga prototipe keempat diteskan untuk melihat keefektifan atau memiliki efek potential dari perangkat pembelajaran yang dibuat dan mengukur kemampuan pemahaman literasi matematika peserta didik.

d. Observasi dan Wawancara

Teknik ini digunakan untuk mengetahui kepraktisan dan keefektifan dari prototipe yang dibuat.

\section{HASIL DAN PEMBAHASAN}

Berikut dijelaskan hasil pengembangan berdasarkan setiap tahapan-tahapan yakni preliminary dan evaluasi formatif yang meliputi self evaluation, expert review, one-to-one, small group, dan field test.

a. Tahap Preliminary

Tahap ini dibagi menjadi dua tahapan yakni analisis/persiapan dan pendesainan Untuk tahap persiapan peneliti menghubungi kepala SMP Kristen Woloan dan berkoordinasi dengan guru mata pelajaran matematika di sekolah terkait yang akan menjadi subjek penelitian.

Selanjutnya, peneliti melakukan tahap analisis yang meliputi analisis siswa, analisis kurukulum dan analisis soal literasi matematika berkaitan dengan kearifan lokal Minahasa. Tahap analisis siswa bertujuan untuk bertujuan mengetahui kemampuan siswa yang menjadi subjek penelitian. Berdasarkan hasil analisis siswa diperoleh 3 orang siswa 
(kemampuan tinggi, sedang, rendah) untuk tahap one-to-one, dan 6 orang siswa pada tahap small group. Untuk tahap analisis kurikulum untuk mengidentifikasi materi pelajaran matematika SMP yang meliputi materi Geometri. Sedangkan analisis soal kemampuan literasi matematika berkaitan dengan kearifan lokal Minahasa dilakukan untuk menjelaskan bagaimana keterkaitan kearifan lokal Minahasa dalam pembelajaran matematika.

Tahap pendesainan dilakukan pendesainan soal berdasarkan analisis yang telah dilakukan sebelumnya.

b. Tahap Evaluasi Formatif

(Formative Evaluation)

a) Self Evaluation

Pada tahap ini peneliti melakukan penilaian sendiri terhadap perangkat yang telah dibuat, atau menilai sendiri hasil pada tahap sebelumnya (pendesainan). Peneliti mengkaji sendiri hasil desain yang telah dibuat, mengecek kesesuaian kearifan lokal Minahasa dan soal kemampuan literasi matematika. Tahapan ini menghasilkan prototipe II.

\section{b) Expert Review (Uji Pakar)}

Pada tahap ini peneliti mengkonsultasikan kepada pakar sebagai validator yaitu dosen matematika Universitas Negeri Manado untuk menelaah konten, konstruk dan bahasa.

\section{c) One-to-one}

Pada tahap ini, desain soal kemampuan literasi matematika (Prototipe I) yang dikembangkan, diuji kepada 3 orang siswa kelas VIII SMP Kristen Woloan yang berkemampuan tinggi, sedang, dan rendah secara individu.

Setelah tahap one-to-one peneliti meminta siswa untuk memberikan pendapat sebagai bahan masukkan terhadap prototipe yang dikembangkan. Berdasarkan validasi pada tahap expert review dan tahap one-to-one maka dilakukan revisi pada prototipe I. Setelah direvisi maka dihasilkan prototipe II.

d) Small Group

Pada tahap ini, diikuti oleh 6 orang siswa yang memiliki tingkat kemampuan yang beragam yakni 2 orang siswa berkemampuan tinggi, 2 orang siswa berkemampuan sedang, dan 2 orang siswa berkemampuan rendah.

Tahap ini dilaksanakan untuk melihat kepraktisan soal yang dikembangkan yaitu prototipe III. Prototipe yang dihasilkan dalam penelitian ini berupa soal literasi matematika untuk tingkat SMP berbasis kearifan lokal Minahasa dalam hal ini rumah panggung Woloan. Soal yang dikembangkan sebanyak tiga soal. Berikut disajikan beberapa pembahasan jawaban siswa. Soal pertama yang dibahas terkait dengan kearifan lokal Minahasa dalam hal ini rumah panggung Woloan yang sudah sering dilihat oleh siswa SMP Kristen Woloan karena sangat dekat dengan keseharian siswa. Soal dikembangkan penulis dengan tujuan agar siswa dapat memahami halhal di sekitar mereka sangat erat kaitannya dengan matematika.

Berikut ditampilkan salah satu soal dan pembahasan jawaban siswa terkait dengan soal yang telah dikembangkan oleh peneliti. Salah satu soal yang dibuat 
adalah konteks plafon rumah panggung yang merupakan salah satu kearifan lokal Minahasa. Penulis bermaksud memunculkan literasi matematika siswa yang berkaitan dengan kehidupan siswa sehari-hari. Konteks pada soal ini berkaitan dengan geometri dan dalam proses penyelesaiannya diperlukan juga konsep pythagoras untuk menentukan ukuran bentuk bangun yang dibuat.

Soal yang dikembangkan bertujuan untuk mengaktifkan kemampuan bernalar siswa untuk menggunakan konsep-konsep matematika dalam berbagai konteks. Penalaran dimulai dari pengamatan bentuk plafon rumah yang berbentuk geometri yang tersusun dari kayu-kayu yang memiliki ukuran yang sama. Berikut ditampilkan soal hasil pengembangan pada Gambar 1.

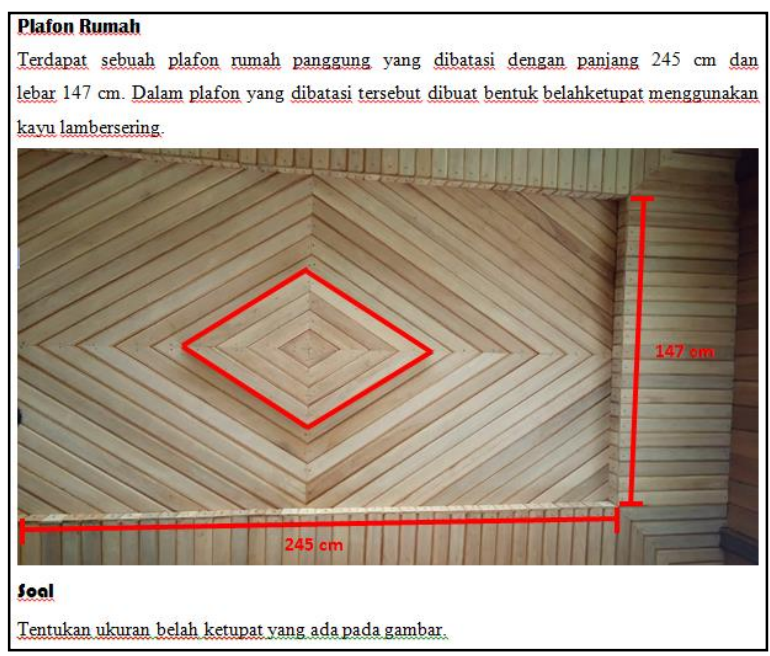

Gambar 1. Soal (Prototipe III)

Dalam menyelesaikan soal yang diberikan, langkah awal yang dilakukan siswa adalah menentukan perkiraan besaran dari masing-masing kayu yang tersusun pada plafon rumah. Dari panjang plafon pada gambar yang diketahui yakni $245 \mathrm{~cm}$. Selanjutnya, siswa menghitung banyaknya kayu yang tersusun sebanyak 35, sehingga siswa dapat menentukan panjang kayu yang tersusun dengan cara $245 \mathrm{~cm}$ dibagi dengan 35 hasilnya adalah $7 \mathrm{~cm}$. Penalaran siswa dalam menyelesaikan soal yang diberikan dapat dilihat pada Gambar 2 berikut.

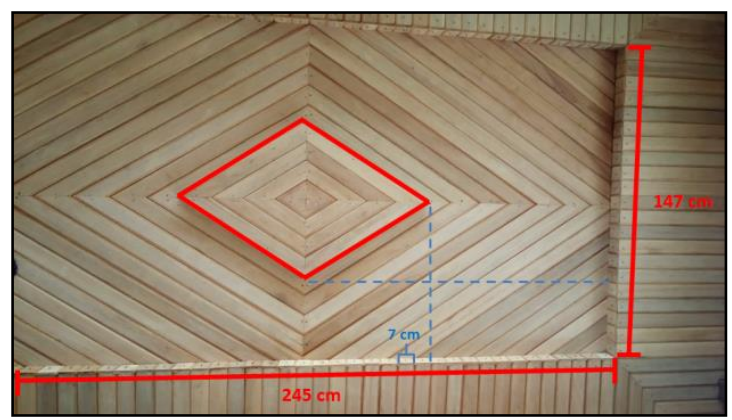

Gambar 2. Penalaran siswa dalam menyelesaikan soal

Setelah itu dapat ditentukan perkiraan panjang dari masing-masing sisi yang membentuk segitiga siku-siku sehingga dapat diperoleh panjang dari sisi miring yang merupakan panjang sisi belah ketupat. Berikut disajikan pada Gambar 3 hasil jawaban siswa dalam menyelesaikan soal yang diberikan.

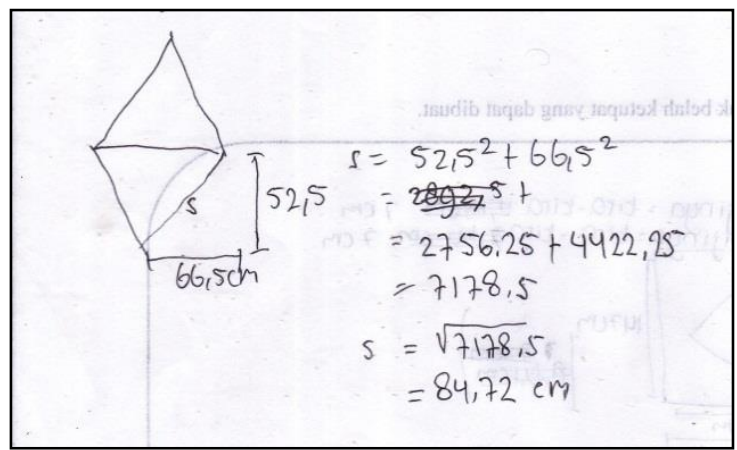

Gambar 3. Hasil Jawaban Siswa

Pada jawaban yang disajikan siswa pada Gambar 3, dapat dilihat siswa melibatkan penalaran yang cukup tinggi dalam menentukan ukuran bentuk belah ketupat yang ada pada plafon rumah panggung.

Berdasarkan analisis jawaban siswa, dapat dilihat siswa mampu menyelesaikan soal yang berkaitan 
dengan kearifan lokal Minahasa yang biasa siswa lihat dalam kehidupan sehari-hari mereka sendiri.

Selain itu, terlihat bahwa soal literasi matematika yang dikembangkan dapat menggali potensi siswa untuk menggunakan berbagai kemampuan matematika dalam menyelesaikan soal yang berkaitan dengan kearifan lokal siswa tersebut.

\section{PENUTUP}

\section{Kesimpulan}

Penelitian ini menghasilkan prototipe soal literasi matematika berbasis kearifan lokal Minahasa. Prototipe yang dikembangkan dapat dikategorikan valid. Disarankan agar guru dapat menggunakan soal literasi matematika berbasis kearifan lokal Minahasa untuk meningkatkan pemahaman siswa dalam menyelesaikan soal literasi matematika.

\section{UCAPAN TERIMA KASIH}

Saya mengucapkan terima kasih sebesar-besarnya kepada Kementerian Riset, Teknologi dan Pendidikan Tinggi melalui LPPM Unima yang telah menyetujui dan membiayai penelitian ini lewat anggaran tahun 2018.

\section{DAFTAR PUSTAKA}

Akker, J. V. (2006). "Introducing Educational Design Research”, dalam Educational Design Research. New York : Routledge

Dwi Astuti, Linda. (2016). Pengembangan Perangkat Pembelajaran Fisika Aktif Tipe Information Search Berbasis Kearifan Lokal DIY untuk Meningkatkan Kemampuan Berpikir Kritis dan Nilai Karakter Siswa SMA. Tesis. Yogyakarta:
Program Pascasarjana, Universitas Negeri Yogyakarta.

Edi, Sedyawati (2006). Budaya Indonesia: Kajian Arkeologi, Seni, dan Sejarah. Jakarta: RajaGrafindo Persada

Gosal, Pierre Holy (2012). Kearifan Lokal Masyarakat Minahasa Membangun Rumah Tinggal yang Hijau dan Nyaman. Media Matrasin Vol. 9 No. 3 November 2012, 67-81

Mangelep, N. (2013). Pengembangan Soal Matematika Pada Kompetensi Proses Koneksi dan Refleksi PISA. Jogjakarta: PPPPTK (Jurnal Edukasi Matematika Vol. 4 No. 7, Juni 2013)

OECD, PISA (2012). Assesment and Analytical Framework: Mathematics, Raeding, Science, Problem Solving and Financial Literacy, Paris: OECD Publisher, 2013.

Permendikbud Nomor 65 Tahun 2013

Rahyono, (2009). Kearifan budaya dalam kata. Jakarta: Wedatama Widya Sastra

Sari, Rosalina. (2015). Literasi Matematika: Apa, Mengapa dan Bagaimana?. Seminar Nasional Matematika dan Pendidikan Matematika UNY.

Tessmer, M. (1993). Planning and Conducting Formative Evaluations. Philadelphia : Kogan Page 
Zuhdan Kun Prasetyo, dkk. (2011). Pengembangan Perangkat Pembelajaran Sains Terpadu Untuk Meningkatkan Kognitif, Keterampilan Proses, Kreativitas serta Menerapkan Konsep Ilmiah Peserta Didik SMP. Program Pascasarjana UNY.

Zulkardi. (2010). How to Design Mathematics Lessons based on the Realistic Approach? Diakses tanggal 4 Februari 2015, dari http://eprints.unsri.ac.id/692/1/rme. html.

\section{RIWAYAT HIDUP PENULIS}

\section{Derel Filandy Kaunang, S.Pd., M.Pd.}

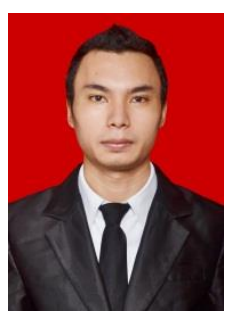
Lahir di Tomohon, tanggal 26 Januari 1990. Staf pengajar di Program Studi Pendidikan Matematika FMIPA Universitas Negeri Manado. Studi S1 Pendidikan Matematika di Universitas Negeri Manado, lulus tahun 2012; S2 Pendidikan Matematika di Universitas Negeri Surabaya, lulus tahun 2014. 